Check for updates

Cite this: RSC Adv., 2018, 8, 38056

Received 24th August 2018

Accepted 2nd November 2018

DOI: $10.1039 / c 8 r a 07076 h$

rsc.li/rsc-advances

\section{Aqueous hybrids of amino-functionalized nanosilica and acrylamide-based polymer for enhanced oil recovery $\uparrow$}

\author{
Jie Cao, (D) *a Tao Song, ${ }^{\text {a }}$ Yuejun Zhu, ${ }^{\text {bc }}$ Xiujun Wang, ${ }^{\text {bc }}$ Shanshan Wang, ${ }^{\text {bc }}$ \\ Jingcheng $\mathrm{Yu}^{\mathrm{a}}{ }^{\mathrm{C}}$ Yin $\mathrm{Ba}^{\mathrm{a}}$ and Jian Zhang ${ }^{\star b c}$
}

Amino-functionalized nanosilica (ANS) was prepared using nanosilica (NS) and 3aminopropyltriethoxysilane (APTES) aiming to reinforce the interaction between nanoparticles and polymer molecules. The copolymer of acrylamide, 2-acrylamido-2-methyl-1-propane sulfonic acid (PM), and four ANS samples with different NS to APTES ratios were synthesized. A series of nanoparticle/polymer hybrid systems were fabricated by introducing NS or ANS suspension into PM aqueous solution. The rheological properties and surface activities of these hybrid systems were studied in comparison with PM. The results indicate that the salt-tolerance and heat-resistance properties of PM solution were improved by the introduction of ANS particles. Moreover, the structures of ANS samples have a significant effect on the effectiveness of the nanoparticles due to the fact that the amine group density on the ANS surface can affect the strength of intermolecular interaction between nanoparticles and polymer molecules. Additionally, the better ability of the ANS sample with proper amine group density showed in reducing the oil/water interfacial tension over NS and other ANS samples made it a more promising chemical for enhancing oil recovery. The results from core flooding tests show that the PM/ANS system has the greatest oil recovery factor (16.30\%), while the values for PM/NS and PM are $10.84 \%$ and $6.00 \%$, respectively.

\section{Introduction}

It is well known that $60-70 \%$ of oil still remains in place in the form of oil droplets or films after primary and secondary recovery. ${ }^{1}$ As energy demand increases day by day and alternative energy sources have not yet proved to satisfy the world's energy demand, it is imperative to find new solutions to recover more oils in the territory recovery. ${ }^{2}$ Polymer flooding is the most commonly used technique in tertiary recovery, especially in Chinese oilfields. ${ }^{3}$ Water-soluble polymers in this application improve the rheological properties of the displacing fluid, especially the viscosity. Conventional flooding polymer, such as partially hydrolyzed polyacrylamide (HPAM), experiences severe degradation under harsh reservoir conditions, for example, high temperature, high salinity (HTHS), and long flooding time (usually 1-12 months). ${ }^{3-7}$

${ }^{a}$ School of Petroleum Engineering, China University of Petroleum (East China), Qingdao 266580, China. E-mail: jcao@upc.edu.cn

${ }^{b}$ CNOOC Research Institute, Beijing 100027, China. E-mail: zhangjian@cnooc.com.cn

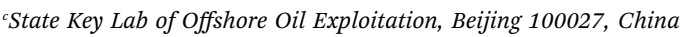

$\dagger$ Electronic supplementary information (ESI) available. See DOI: $10.1039 / \mathrm{c} 8 \mathrm{ra0} 07076 \mathrm{~h}$
The application of nanoparticles in surface engineering has accelerated the development of nanotechnology and numerous new materials with a series of functional properties and applications have been developed. ${ }^{8-10}$ Nanoparticles have a number of favorable characteristics such as high surface area, special optical and chemical responses, and active surfaces for application in the petroleum industry. ${ }^{\mathbf{1 1}}$ Nanosilica (NS) is one of the most widely used inorganic nanoparticles in industry, which can be obtained easily, and the physical-chemistry properties of silica surfaces and interfaces are well-known. ${ }^{\mathbf{1 2 - 1 5}}$ Nanoparticles can pass through the pore throat in typical reservoir and thus access residual oil microscopically. They can reduce oil/water interfacial tension and alter rock surface wettability through their surface activity, and hence reduce the capillary force that oil phase needs to overcome to be mobilized. ${ }^{16,17}$ Nanoparticles can also modify some properties of the displacing fluid, such as viscosity, density, surface tension, thermal conductivity and specific heat-tolerance..$^{12,18-21}$ It has been reported that the addition of NS could increase the viscosity and enhance the heat-tolerance of polymer solution. ${ }^{19,22-24}$ The strong interaction between NS and polymer is mainly attributed to the formation of hydrogen bond between hydroxyl group on NS surface and functional groups on polymer molecule, such as hydroxyl, amide and 
carboxylate groups. Thus, NS can act as physical crosslinkers between different polymer molecules, which reinforces molecular network structure and enhances the rheological property of polymer solution. ${ }^{23}$ Moreover, because of the competitive attraction to cationic salt ions between NS and polymer, the degradation of the polymer molecules could be inhibited in salt solution, especially when the concentration of $\mathrm{Ca}^{2+}$ or $\mathrm{Mg}^{2+}$ is high. ${ }^{24-26}$ But the specific interaction mechanisms between NS and polymer molecules are still unknown and further studies should be focused on that.

However, with a negatively charged surface, the commonly used flooding polymer can only interact with NS through hydrogen bond and van der Waals when the $\mathrm{pH}$ ranges from 3 to $10 .^{27}$ This lowers down the amount of the polymer adsorbed on NS surface, and the molecular network structures crosslinked by NS are weak. Additionally, NS tends to agglomerate or even precipitate if it is not well dispersed, and it often shows poor compatibility with polymer in solution. ${ }^{28-30}$ For example, it may take 3 days or even longer to get a well-dispersed hybrid of nanoparticle and HPAM. ${ }^{31}$ Amino-grafted nanosilica (ANS) can make up these disadvantages mentioned above. ANS is positively charged under acidic, neutral and weakly alkaline conditions which gives it a better interaction with the negatively charged polymer through stronger coordination bond rather than weaker hydrogen bond and van der Waals force. As a result, the effect of ANS on the rheological property of polymer solution is much more significant and this makes ANS a better candidate for EOR polymers than NS.

In our previous work, we found that ANS gave an obvious improvement of the heat-resistance of acrylamide-based polymer at high temperature, and the addition of ANS reduced the hydrolysis of amide groups and the rupture of polymer backbones through specific interactions between ANS and polymer. ${ }^{32}$ In this paper, we further investigated the effect of ANS structures on the performance improvement of polymer solution. Four ANS samples with different amine group densities were prepared. These ANS samples and NS were introduced into an acrylamide-based polymer solution respectively to fabricate nanoparticle/polymer hybrid. The rheological and interface properties of these hybrids were studied, and the oil displacement experiments for three typical samples were also performed to study their EOR ability.

\section{Materials and methods}

\subsection{Experimental materials}

Nanosilica (NS), 3-aminopropyltriethoxysilane (APTES, 99\%), acrylamide (AM, 99\%), 2-acrylamido-2-methyl-1propanesulfonic acid (AMPS), triethylamine (TEA, 99\%), 2,2'azobis(2-methylpropionamidine)dihydrochloride (AIBA, 99\%) were purchased from Shanghai Aladdin Biochemical Technology Co. Ltd. and utilized without further purification. The diameter of NS was ranging from 7 to $40 \mathrm{~nm}$, and the surface area was $380 \mathrm{~m}^{2} \mathrm{~g}^{-1}$. The content of hydroxyl groups in NS was $0.60 \mathrm{mmol} \mathrm{g}^{-1}$ estimated by titration with $\mathrm{NaOH}$ $\left(0.05 \mathrm{~mol} \mathrm{~L}^{-1}\right) \cdot{ }^{33}$ Other materials were analytical reagent and used as received.

\subsection{Synthesis}

2.2.1. Preparation of amino-functionalized nanosilica. Amino-functionalized nanosilica was obtained by modifying NS using APTES at a weakly alkaline condition. $6.0 \mathrm{~g}$ of NS was added into $100 \mathrm{~mL}$ of $\mathrm{CH}_{3} \mathrm{CH}_{2} \mathrm{OH}$ and dispersed by magnetic stirring for $2 \mathrm{~h}$ at room temperature. A certain amount of APTES was dissolved in $100 \mathrm{~mL}$ of $\mathrm{CH}_{3} \mathrm{CH}_{2} \mathrm{OH} / \mathrm{H}_{2} \mathrm{O}(\mathrm{v} / \mathrm{v}, 9 / 1)$. After this, the NS dispersion, APTES solution and TEA $(2.5 \mathrm{~mL})$ were introduced into a flask and the modification was performed at $80^{\circ} \mathrm{C}$ for $4 \mathrm{~h}$. The crude product was filtered and washed with $\mathrm{CH}_{3} \mathrm{CH}_{2} \mathrm{OH}$. Then, ANS was obtained after being dried in vacuo at $80{ }^{\circ} \mathrm{C}$ for $24 \mathrm{~h}$. Four ANS samples were synthesized as showed in Table 1.

2.2.2. Preparation of polymer. The copolymer of AM and AMPS (PM) was prepared through radical polymerization. $5.8 \mathrm{~g}$ of AM and $4.2 \mathrm{~g}$ AMPS were dissolved in $90 \mathrm{~g}$ of distilled water and the $\mathrm{pH}$ value was adjusted to around 8 by $\mathrm{NaOH}$. After this, the monomer solution was added into a three-neck flask and stirred with an electric stir bar under an inert $\mathrm{N}_{2}$ atmosphere for $30 \mathrm{~min}$. Then $0.025 \mathrm{~g}$ of AIBA was introduced into the system to trigger the reaction. The system was maintained at $60{ }^{\circ} \mathrm{C}$ for $12 \mathrm{~h}$ to obtain crude product. The produced gel was cut into small pieces and then washed by $\mathrm{CH}_{3} \mathrm{CH}_{2} \mathrm{OH} / \mathrm{H}_{2} \mathrm{O}(\mathrm{v} / \mathrm{v}, 7 / 3)$ twice for $6 \mathrm{~h}, \mathrm{CH}_{3} \mathrm{CH}_{2} \mathrm{OH} / \mathrm{H}_{2} \mathrm{O}(\mathrm{v} / \mathrm{v}, 9 / 1)$ once for $6 \mathrm{~h}$, and $\mathrm{CH}_{3} \mathrm{CH}_{2} \mathrm{OH}$ twice for $12 \mathrm{~h}$. The product was sieved and dried in vacuo at $60{ }^{\circ} \mathrm{C}$ for $48 \mathrm{~h}$.

2.2.3. Preparation of nanoparticle/polymer hybrid. NS or ANS samples were fully dispersed in distilled water by ultrasonication for $1 \mathrm{~h}$ to form a stable dispersion. The appropriate $\mathrm{pH}$ value (ranging from 3 to 11) was adjusted using dilute $\mathrm{NaOH}$ or $\mathrm{HCl}$ solution. Polymer solution was prepared by adding PM powders to distilled water while stirring on a magnetic stirrer for $24 \mathrm{~h}$. The hybrid sample was prepared by mixing nanoparticle suspension with PM solution. The mixture was gently stirred for 3 days. In the following experiments, unless otherwise noted, the PM and nanoparticle concentrations were $0.25 \mathrm{wt} \%$ and $0.1 \mathrm{wt} \%$, respectively.

\subsection{Rheology measurement}

Rheology properties were measured using a Haake Mars 60 rheometer (Thermo Fisher Scientific Instrument Ltd, USA). Under steady shear, the flow curves for apparent viscosity and shear stress with respect to shear rate were recorded with shear rate varying between $0.01 \mathrm{~s}^{-1}$ and $1000 \mathrm{~s}^{-1}$. For oscillatory shear, at first, stress-sweep measurement was performed to find out the linear viscoelastic region. Thereafter all the dynamic frequency behavior of sample was taken in this viscoelastic region. The apparent viscosities of every solution under different conditions were determined when the shear rate was $7.34 \mathrm{~s}^{-1}$.

\subsection{Interfacial tension measurement}

Pendant drop method was used to determine the interfacial tension between hybrid solution and oil phase. Optical interfacial tension meter (Solon Tech. SL200KS, USA) was used to 
Table 1 Composition and zeta potential of ANS samples

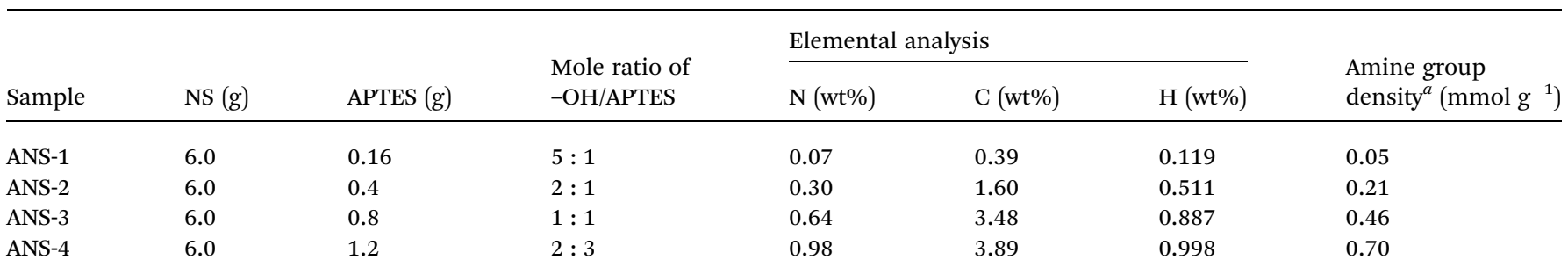

${ }^{a}$ Determined via elemental analysis.

take the measurement. The pendant drop is an oil drop suspended from a needle in a water bulk liquid. The interfacial tension was calculated from the shadow image of the pendant oil drop using drop shape analysis method.

\subsection{Zeta potential and dynamic light scattering measurements}

The zeta potentials and average diameters of different nanoparticles were measured with a Zeta Meter 3.0 (Zeta Meter Inc., USA) equipped with a microprocessor unit. The average of 5 measurements was taken to represent the measured zeta potential.

\subsection{Core flooding experiment}

A three-layer artificial vertical heterogeneous high-permeability core (each vertical heterogeneous layer's permeability was 200/ $500 / 1500 \mathrm{mD}$ ) were prepared for the flooding experiment. The density of dehydrated Bohai oil was $0.94 \mathrm{~g} \mathrm{~cm}^{-3}$, and the viscosity was $15.8 \mathrm{mPa}$ s at $70{ }^{\circ} \mathrm{C}$. The core was saturated with simulated brine $\left(3091.96 \mathrm{mg} \mathrm{L}^{-1} \mathrm{Na}^{+}\right.$and $\mathrm{K}^{+}, 276.17 \mathrm{mg} \mathrm{L}^{-1}$ $\mathrm{Ca}^{2+}, 158.68 \mathrm{mg} \mathrm{L}^{-1} \mathrm{Mg}^{2+}, 14.21 \mathrm{mg} \mathrm{L}^{-1} \mathrm{CO}_{3}{ }^{2-}, 311.48 \mathrm{mg} \mathrm{L}^{-1}$ $\mathrm{HCO}_{3}{ }^{-}, 85.29 \mathrm{mg} \mathrm{L}{ }^{-1} \mathrm{SO}_{4}{ }^{2-}$, and $5436.34 \mathrm{mg} \mathrm{L}^{-1} \mathrm{Cl}^{-}$, TDS $9374 \mathrm{mg} \mathrm{L}^{-1}$ ), followed by injecting the hydrated Bohai oil to around $80 \%$ oil saturation. The core was then injected with simulated brine until the water cut was greater than $98 \%$. After this, 0.3 pore volume (PV) of the sample solution was injected.

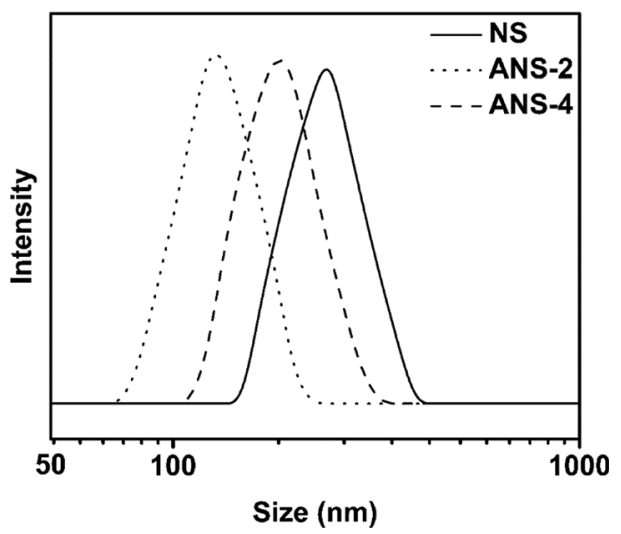

Fig. 1 Particle size distributions of NS and ANS in distilled water at $\mathrm{pH}$ 6.0.
The total oil recovery and the oil recovery by water flooding were recorded, and the differences between them are defined as the tertiary oil recovery factors by PM, PM/NS or PM/ANS flooding. The injection rate of the sample was maintained at 0.1 $\mathrm{mL} \min ^{-1}$, and the core was placed in a chamber and maintained at $70{ }^{\circ} \mathrm{C}$ throughout the test.

\section{Results and discussion}

\subsection{Characterization of ANS}

For ANS samples, the modification process and the density of amine groups on particle surface have been analyzed in detail in our previous work. ${ }^{32}$ As shown in Table 1, the amine group density on ANS surface increases with the increase of APTES feeding amount. The hydrodynamic particle size distributions for NS and ANS samples in distilled water are shown in Fig. 1. Among ANS samples, the diameter increases with the increase of amine group density. ANS-2 possesses one peak around $134 \mathrm{~nm}$, ANS-4 possesses one peak around $179 \mathrm{~nm}$. The reason for the increase of diameter might be that the hydration layer of particle increases with the increase of charge density on its surface. However, NS shows larger diameter than any ANS sample, and it possesses one peak around $240 \mathrm{~nm}$. It has been reported that NS particles are highly aggregated and irregular shaped at $\mathrm{pH}$ value below $9 .^{34}$

Fig. 2 shows zeta potential as a function of $\mathrm{pH}$ for NS and ANS. One can see that zeta potential was strongly dependent on the suspension $\mathrm{pH}$. The surface of NS is negatively charged in

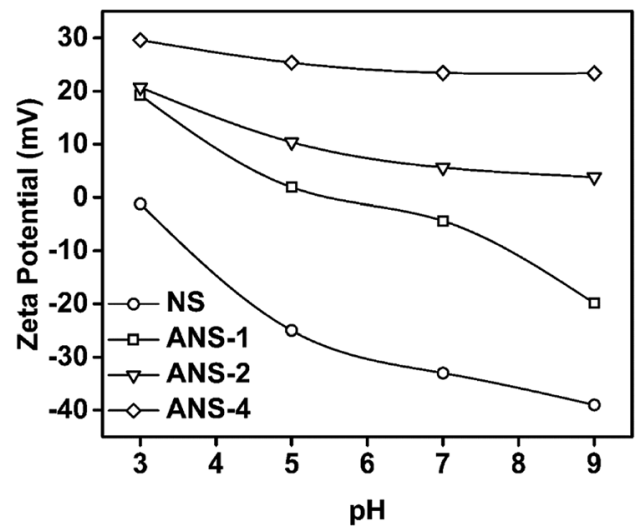

Fig. 2 Variation of zeta potential as a function of $\mathrm{pH}$. 
the whole $\mathrm{pH}$ range studied from 3 to 9 . There were two kinds of silanol groups: isolated silanol groups (about 19\%, $\mathrm{p} K_{\mathrm{a}}=4.9$ ) and vicinal ones (about $81 \%, \mathrm{p} K_{\mathrm{a}}=8.5$ ). The absolute value of zeta potential increases with the increase of $\mathrm{pH}$, which can be attributed to the dissociation of isolated silanol groups and vicinal silanol groups. ${ }^{35,36}$ As for ANS, its zeta potential is determined by the dissociation of both silanol groups and amine groups. Due to the protonation of amine groups, the samples with high amine group density, such as ANS-2 and ANS-4, were positive charged in whole studied $\mathrm{pH}$ range. However, ANS-1 was negatively charged when its $\mathrm{pH}$ was greater than 7 , which means the dissociation of silanol groups plays a dominant role in determining the charge type of particles. Due to the difference in functional groups and charge situation on ANS samples, it is expected that, in nanoparticle/polymer hybrid suspension, the interaction between ANS and polymer is affected by ANS type and suspension $\mathrm{pH}$.

\subsection{Effect of nanoparticle type and concentration on the} viscosity of polymer/nanoparticle hybrid

The rheological behavior of polymer/nanoparticle hybrid largely depends on the nanoparticle type and concentration. A PM solution was prepared as the reference solution in which a series of nanoparticles were added. As shown in Fig. 3a, all nanoparticle-based systems exhibit greater viscosity than PM in $\mathrm{NaCl}$ solution. In ANS-based systems, PM/ANS-2 has the greatest viscosity. When the $\mathrm{NaCl}$ concentration increases to $9000 \mathrm{mg} \mathrm{L}^{-1}$, a similar result can be also found (see ESI, Fig. S1 $\dagger$ ). However, PM/ANS-4 has the greatest viscosity in $\mathrm{CaCl}_{2}$ solution as shown in Fig. S1. $\dagger$ As a result, PM/ANS-2 and PM/ ANS-4 are chosen for further study. The effect of nanoparticle concentration on the viscosity of nanoparticle/polymer hybrids is shown in Fig. 3b. It has been reported that nanoparticles can act as physical crosslinkers for different polymer molecules to form a network structure in solution via hydrogen bond or other intermolecular interactions..$^{\mathbf{2 8 , 3 1}}$ With the increase of nanoparticle concentration, the incremental viscosity can be attributed to the interaction enhancement between different nanoparticles, and between nanoparticles and polymer molecules. The functional group type and concentration on nanoparticle surface also have a significant influence on the interaction strength.

\subsection{Effect of electrolyte on the viscosity of polymer/ nanoparticle hybrid}

In order to evaluate the stability of nanoparticle/polymer hybrid in different salt solutions, the apparent viscosities of different samples were measured and the results are shown in Fig. 4, 5, S2 and S3. $\dagger$ The viscosity of all kinds of solution keeps decreasing upon the addition of $\mathrm{NaCl}$. All hybrid samples show a higher reserved viscosity than PM, which indicates the improvement of salt-tolerance for acrylamide-base polymer by nanoparticles. And among the three nanoparticle samples, ANS2 exhibits the best property in whole studied salinity range. As shown in Fig. 5, PM/ANS samples exhibit greater viscosity than $\mathrm{PM}$ or $\mathrm{PM} / \mathrm{NS}$ in the whole tested $\mathrm{CaCl}_{2}$ concentration range.
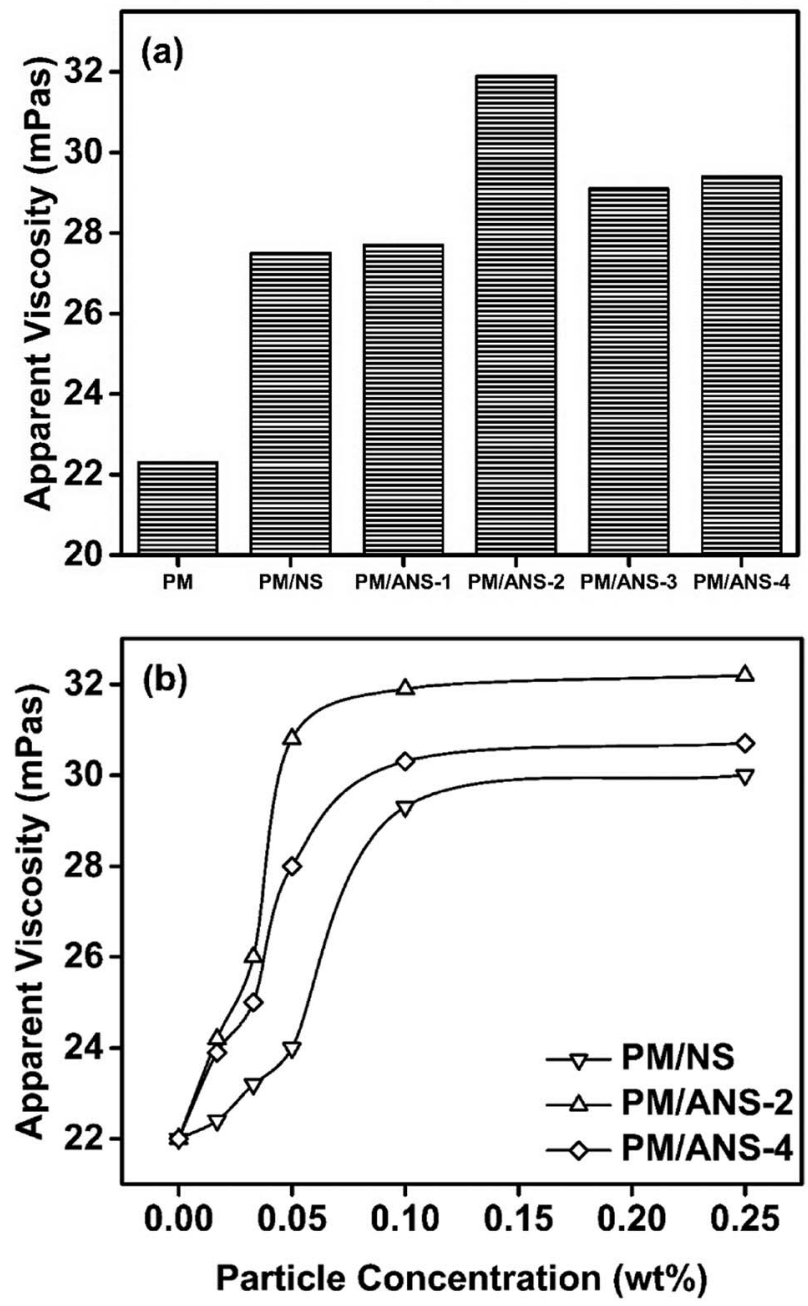

Fig. 3 Apparent viscosity plotted as a function of (a) nanoparticle type and (b) nanoparticle concentration $\left(25^{\circ} \mathrm{C}, \mathrm{NaCl} 3000 \mathrm{mg} \mathrm{L}^{-1}\right.$ ).

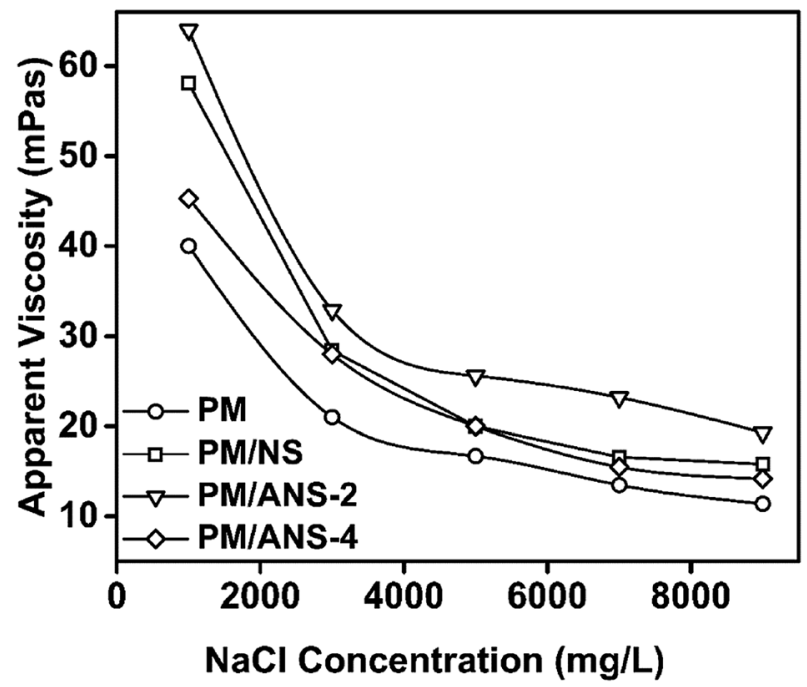

Fig. 4 Apparent viscosity plotted as a function of $\mathrm{NaCl}$ concentration at $25^{\circ} \mathrm{C}$. 


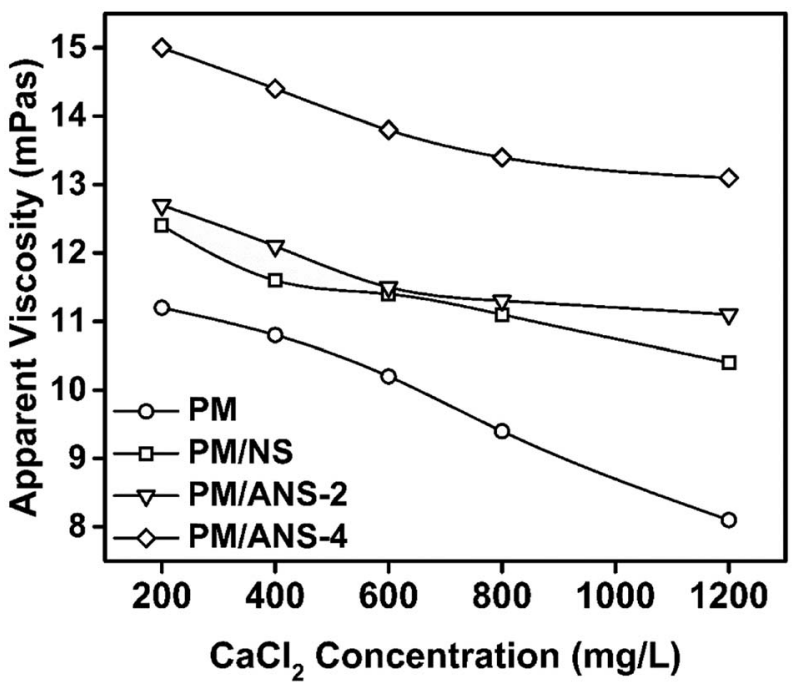

Fig. 5 Apparent viscosity plotted as a function of $\mathrm{CaCl}_{2}$ concentration at $25^{\circ} \mathrm{C}$.

Additionally, the viscosities of PM and PM/NS keep decreasing with the increase of $\mathrm{CaCl}_{2}$ concentration, however, the viscosity of PM/ANS-2 or PM/ANS-4 remains constant when the concentration of $\mathrm{CaCl}_{2}$ is larger than $800 \mathrm{mg} \mathrm{L}^{-1}$.

Once salt is added into polymer solution, the negative charged groups are screened and there is a decrease in repulsion between polymer molecules. So the polymer chains transit from stretched status to shrinkable status and its hydrodynamic radius decreases. The divalent ion has higher charge density than monovalent ion because it has stronger interaction with polymer chains. ${ }^{24,35,37}$ The hydrogen bond between polymer and nanoparticles could be broken or weaken by the divalent metal cations, especially by $\mathrm{Ca}^{2+} \cdot{ }^{36-39}$ As a result, the efficiency of divalent ions to reduce the viscosity of polymer solution is much greater than monovalent ions. In PM/ANS solution, amine group can be protonated and become positively charged. ${ }^{40}$ The interaction between ANS particles and polymer molecules is much greater due to the additional electrostatic attraction between the charged amine groups and the ionic groups in polymer molecules. ${ }^{32}$ Compared to $\mathrm{PM} / \mathrm{NS}$ solution, the stronger network formed by ANS particles and polymer molecules is the reason for the higher viscosity of the PM/ANS solution.

As shown in Fig. 6, in $\mathrm{NaCl}$ solution, the network structure between polymer chains and ANS-2 could remain steady because the interaction between $\mathrm{Na}^{+}$and functional groups, such as $-\mathrm{NH}_{2},-\mathrm{CONH}_{2}$ and $-\mathrm{SO}_{3}{ }^{-}$, is not strong enough to break or weaken the hydrogen bond and electrostatic attraction between PM molecules and ANS particles. ${ }^{36-39}$ However, due to its high amine group density, the electrostatic attraction between ANS-4 particles and PM molecules becomes so strong that the PM molecules could be adsorbed on ANS-4 surface at many locations, which would increase the reduction in apparent size of polymer molecule. The crosslinking effect by ANS-4 particles could be excessive in this situation. During the experiment we found that PM/ANS-3 and PM/ANS-4 tended to aggregate when the concentration of particle was over $1 \mathrm{wt} \%$, while PM/ANS-2 remained stable. Moreover, the high amine

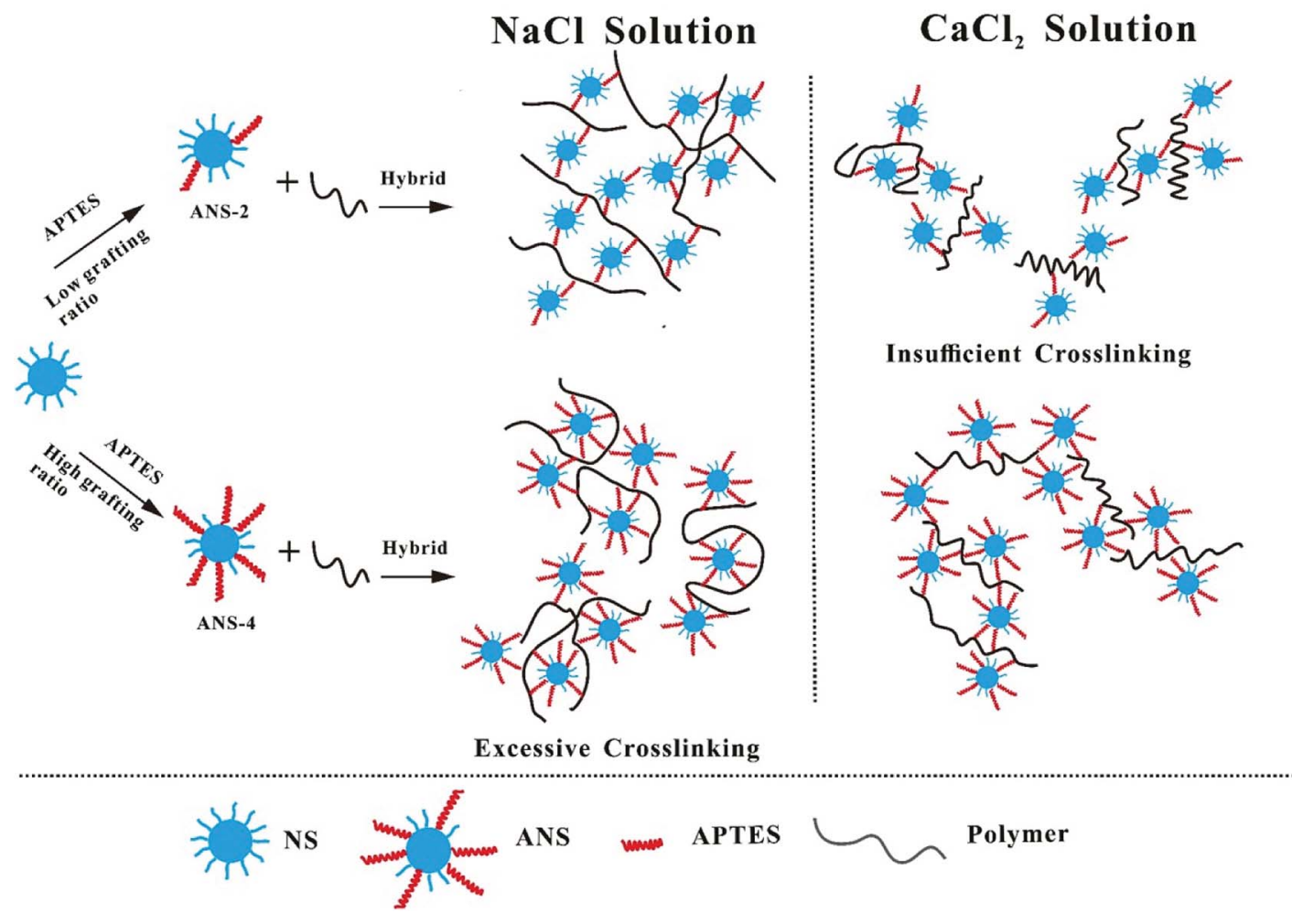

Fig. 6 Schematic representation of the hybrid structure for PM/ANS-2 and PM/ANS-4 in $\mathrm{NaCl}$ and $\mathrm{CaCl}_{2}$ solutions. 
group could also enhance the electrostatic repulsion between different PM/ANS-4 aggregations. As a result, PM/ANS-4 shows less reserved viscosity than $\mathrm{PM} / \mathrm{ANS}-2$ in $\mathrm{NaCl}$ solution. Compared to $\mathrm{Na}^{+}$ion, $\mathrm{Ca}^{2+}$ ion has stronger ability to break hydrogen bond and weaken electrostatic attraction between nanoparticles and polymer molecules. ${ }^{37}$ As a result, in PM/ANS2 system, hydrogen bond plays an important role in the formation of network structure due to the great hydroxyl group concentration on ANS-2 surface, and the addition of $\mathrm{Ca}^{2+}$ greatly destroys the network structure. The crosslinking effect by ANS-2 might be insufficient in this situation. However, in PM/ANS-4 system, due to the decrease of the interaction between nanoparticles and PM molecules, the agglomerated polymer molecules could be re-isolated, which makes polymer molecules a stretched status. Thus, PM/ANS-2 has better NaCl tolerance property, and PM/ANS-4 has better $\mathrm{CaCl}_{2}$ tolerance property.

\subsection{Effect of the temperature on the viscosity of polymer/ nanoparticle hybrids}

The viscosity loss of acrylamide-based polymer at elevated temperature inhibits its application in high temperature reservoir. The effect of temperature on the apparent viscosities of PM and three hybrid samples is shown in Fig. 7 and S4. $\dagger$ It is found that the apparent viscosities of all samples undergo a sharp decrease as the temperature increases. For polymer solution at high temperature, the mobility of molecules is increased, which leads to decreased intermolecular interaction and weakened molecular network. Among the four samples, $\mathrm{PM} / \mathrm{ANS}-2$ system has the higher viscosity when the temperature is lower than $60^{\circ} \mathrm{C}$, and PM/ANS-4 has the higher viscosity when the temperature is higher than $60{ }^{\circ} \mathrm{C}$. The interaction between ANS-2 and PM was not strong enough to maintain the viscosity of the hybrid system at high temperature. However, to some extent, the "excess crosslinking effect of ANS-4" could compensate for the loss of viscosity under high temperature conditions. The highest viscosity obtained by ANS/polymer hybrid indicates that the molecular network partly formed by

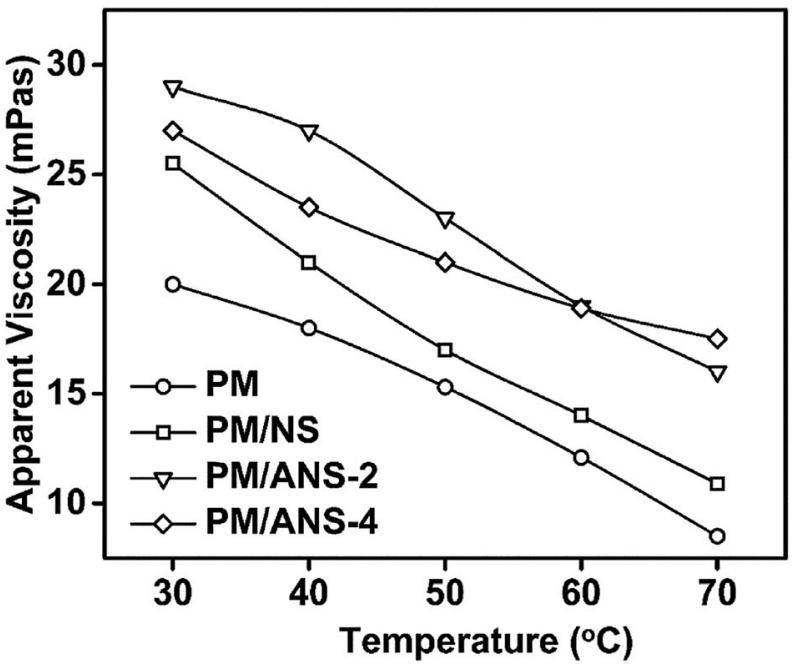

Fig. 7 Apparent viscosity plotted as a function of temperature in salt solution ( $\mathrm{NaCl} 3000 \mathrm{mg} \mathrm{L}^{-1}, \mathrm{CaCl}_{2} 400 \mathrm{mg} \mathrm{L}^{-1}$ ).
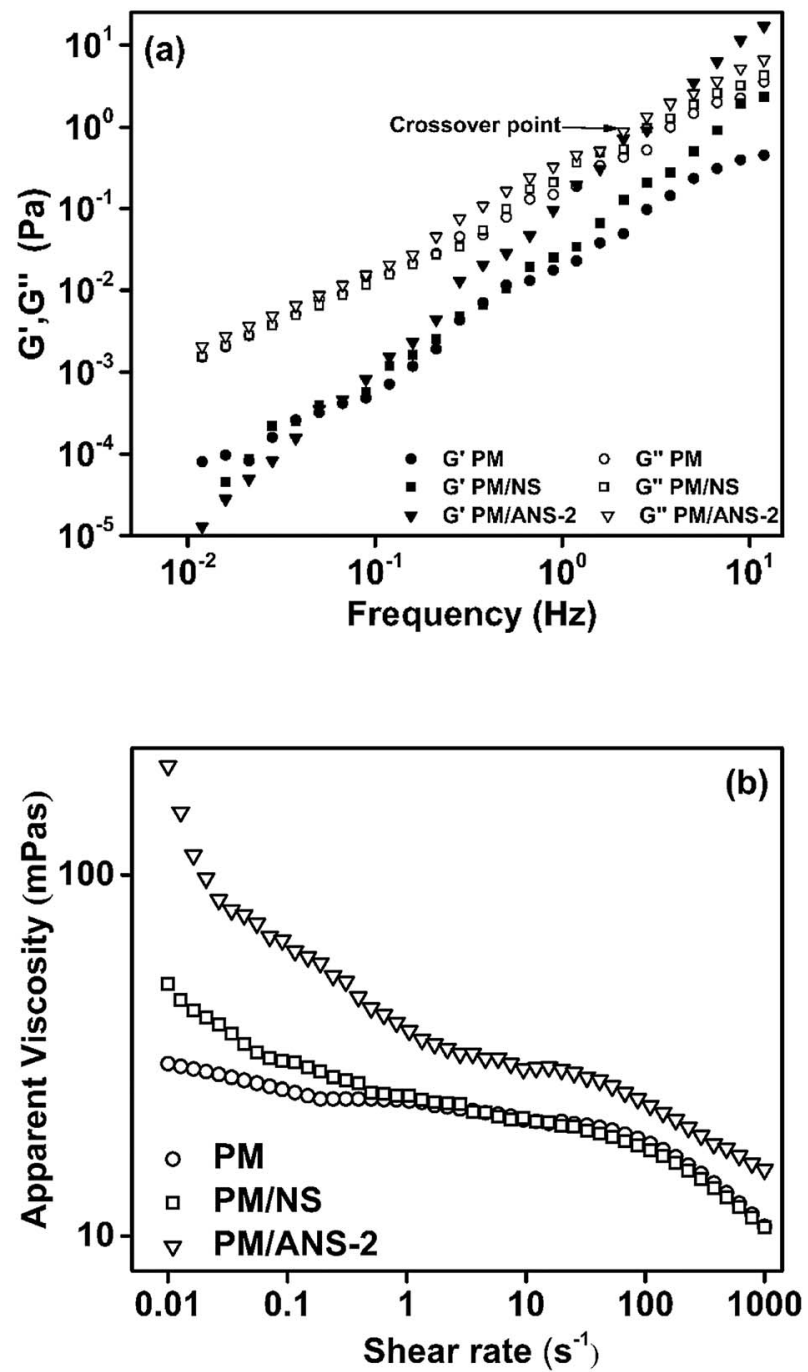

Fig. 8 (a) Storage modulus $\left(G^{\prime}\right)$ and loss modulus $\left(G^{\prime \prime}\right)$ as a function of frequency $(\mathrm{Hz})$ in $\mathrm{NaCl}\left(3000 \mathrm{mg} \mathrm{L}^{-1}\right)$ solution at $25^{\circ} \mathrm{C}$. (b) Apparent viscosity as a function of shear rate in $\mathrm{NaCl}\left(3000 \mathrm{mg} \mathrm{L}^{-1}\right.$ ) solution at $25^{\circ} \mathrm{C}$.

electrostatic attraction is much more stable than that only formed by hydrogen bond and van der Waals force.

\subsection{Viscoelastic behavior of nanoparticle/polymer hybrid}

Generally, water-soluble polymer solution exhibits viscous behavior when flowing through capillary tubes. In porous media where capillary diameters change rapidly, polymer chains are pulled and contracted to exhibit elastic behavior, and the flow is elongational or extensional. Four mechanisms pulling mechanism, stripping mechanism, the mechanism of oil-thread flow, and the mechanism of shear-thickening effect, have been discovered for a viscoelastic polymer solution to reduce residual-oil saturation. ${ }^{\mathbf{4 1 , 4 2}}$ Oscillatory tests were performed for PM, PM/NS solution and PM/ANS-2 solutions. The storage modulus $\left(G^{\prime}\right)$ is the characteristic of elastic behaviors and loss modulus $\left(G^{\prime \prime}\right)$ is the characteristic of viscous behaviors. When $G^{\prime}>(<) G^{\prime \prime}$, the suspension exhibits viscoelastic gel-like behavior (liquid-like behavior). As shown in Fig. 8a, for all 

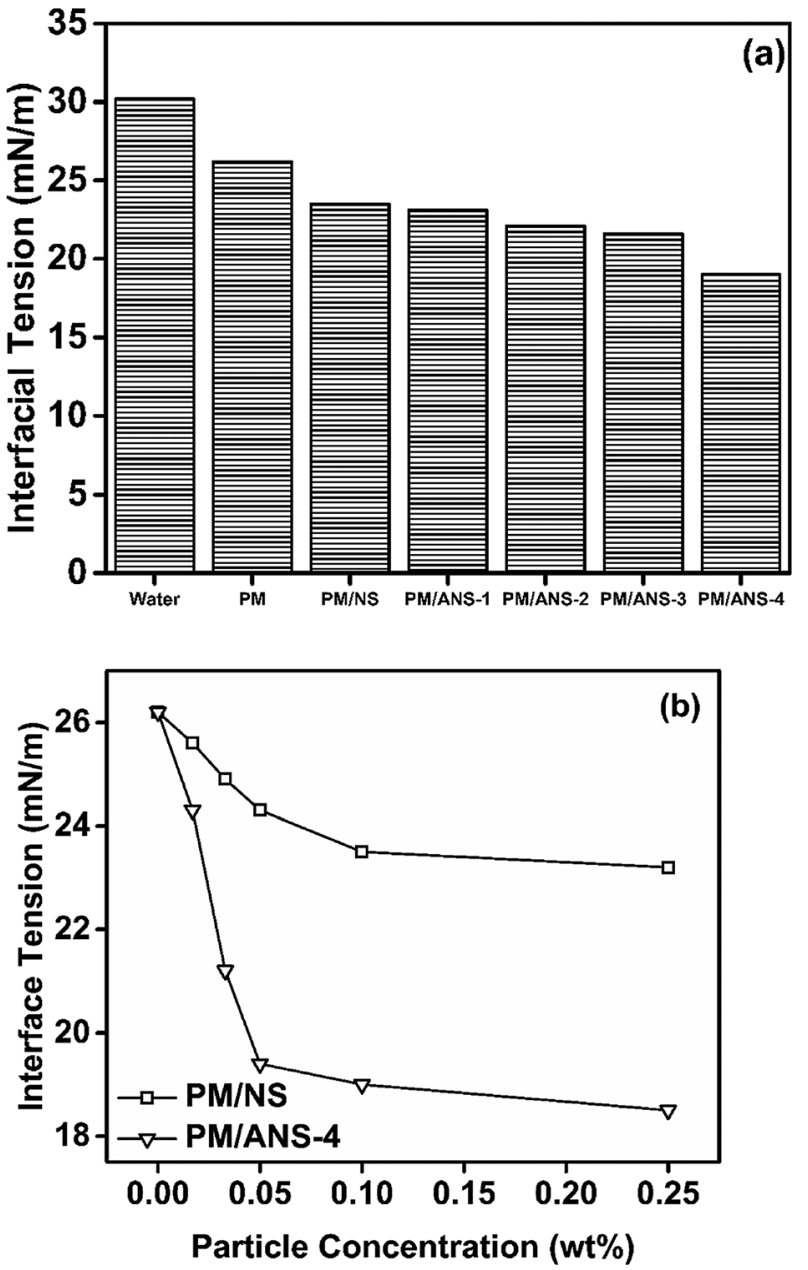

Fig. 9 (a) Interfacial tension measured at different hybrid systems at $25^{\circ} \mathrm{C}$. (b) Interfacial tension as a function of nanoparticle concentration at $25^{\circ} \mathrm{C}$.

systems, the values of $G^{\prime}$ and $G^{\prime \prime}$ increase with the increase of frequency. With the addition of nanoparticles, $G^{\prime}$ of PM/ANS-2 solution is greater than that of $\mathrm{PM}$ and $\mathrm{PM} / \mathrm{NS}$ solutions. From the shape of $G^{\prime}$, it can be concluded that PM and PM/NS solution had a long-term relaxation time because of insufficient network structure between polymer molecules or between polymer molecules and nanoparticles. ${ }^{22}$ Due to the formation of a stable 3D network structure by the introduction of ANS particles, the relaxation time of PM/ANS-2 solution is less than PM and PM/NS solutions, which indicates a large elasticity.

In steady state shear measurement, the apparent viscosity of polymer solution increases with the decrease of shear rate at relatively low shear rate, which is mainly related to the orientation of polymer molecules along the streamline of flow and to the disentanglement of polymer molecules with the increasing shear force.$^{41}$ The viscosity related to this type of flow is shearthinning viscosity. Fig. 8b shows the viscosities of PM, PM/NS and PM/ANS-2 solutions under different shear rates. It shows that PM/ANS-2 has the highest viscosity in the whole studied shear rate changing from 0.01 to $1000 \mathrm{~s}^{-1}$ and the viscosity gradually reduced with the increase of shear rate, indicating the shear-thinning property.
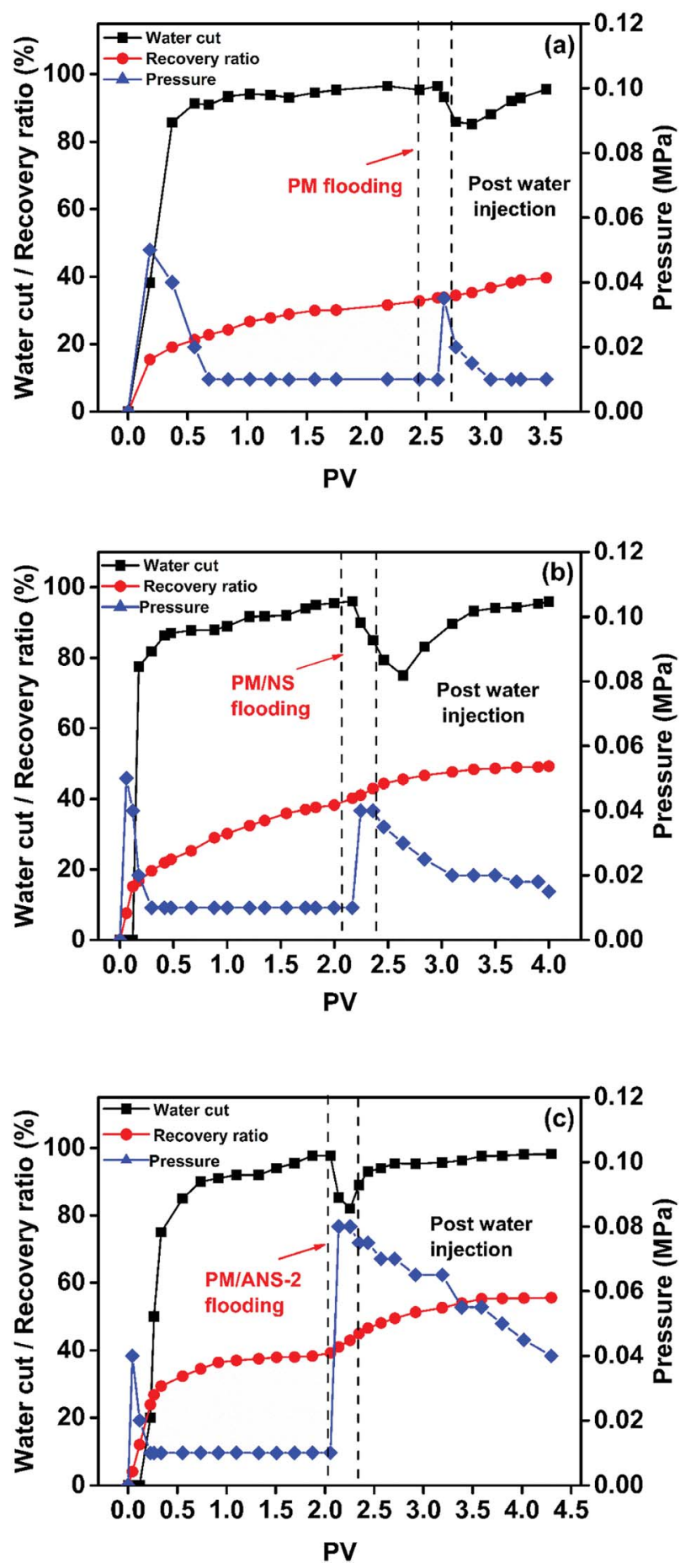

Fig. 10 Oil recovery factor, water cut, and flooding pressure plotted as a function of injected volume of the samples: (a) PM solution, (b) PM/ NS solution, (c) PM/ANS-2 solution.

\subsection{Effect of nanoparticle type and concentration on oil/} water interfacial tension

In petroleum industry, the reduction of oil/water interfacial tension is one of the mechanisms for chemical EOR. Nanoparticles have a strong effect on the oil/water interfacial tension, and among the numerous inorganic nanoparticles, NS has the 
Table 2 Core parameters and oil recovery factors for oil displacement test

\begin{tabular}{|c|c|c|c|c|c|c|c|c|}
\hline Core no. & $\begin{array}{l}\text { Permeability } \\
(\mathrm{mD})\end{array}$ & $\begin{array}{l}\text { Pore volume } \\
\left(\mathrm{cm}^{3}\right)\end{array}$ & $\begin{array}{l}\text { Saturated } \\
\text { oil }\left(\mathrm{cm}^{3}\right)\end{array}$ & Slug & $\begin{array}{l}\text { Slug } \\
\text { injected (PV) }\end{array}$ & $\begin{array}{l}\text { Water flooding } \\
\text { recovery }(\%)\end{array}$ & $\begin{array}{l}\text { Ultimate } \\
\text { recovery (\%) }\end{array}$ & $\begin{array}{l}\text { Oil recovery } \\
\text { factor }(\%)\end{array}$ \\
\hline 1 & 319.79 & 95.0 & 68 & PM & 0.3 & 33.75 & 39.75 & 6.00 \\
\hline 2 & 340.56 & 73.2 & 58 & PM/NS & 0.3 & 38.36 & 49.20 & 10.84 \\
\hline 3 & 360.80 & 110.0 & 100 & $\begin{array}{l}\text { PM/ANS- } \\
2\end{array}$ & 0.3 & 39.20 & 55.50 & 16.30 \\
\hline
\end{tabular}

best ability in reducing oil/water interfacial tension. ${ }^{14}$ The interfacial tension measurement was conducted for a crude oil against different hybrid solutions, and the results are presented in Fig. 9a. Compared to PM solution, the introduction of NS or ANS particles both decreases interfacial tension. All ANS samples exhibit better property of reducing interfacial tension than NS. With the increase of amine group density, the ability of these ANS samples in reducing interfacial tension increases. Fig. 9b presents the interfacial tension as a function of nanoparticle concentration for PM/NS and PM/ANS-4. A sharp decrease of interfacial tension is observed in both system at low nanoparticle concentration. However, when the concentration is above a critical value, a balanced interfacial tension could be obtained. The critical concentrations are $0.1 \mathrm{wt} \%$ and $0.05 \mathrm{wt} \%$, and the balanced interfacial tensions are around $19 \mathrm{mN} \mathrm{m}^{-1}$ and $24 \mathrm{mN} \mathrm{m}^{-1}$ for PM/NS and PM/ANS-4, respectively.

The adsorption of nanoparticles at the oil/water interface lowers the interfacial tension of nanoparticle/polymer hybrid. ${ }^{43}$ Nanoparticles adsorb at the interface primarily to reduce the area of the high-energy oil/water interface. ${ }^{44,45}$ It is well known that the reduction in interfacial tension due to the adsorption of a surface active agent is controlled by the overall hydrophobicity or hydrophilicity. An appropriate hydrophilic character would reduce the interfacial tension. ${ }^{44} \mathrm{PM}$ molecules, composed of AM and AMPS units, are hydrophilic in nature, thus, nanoparticle/ polymer hybrids will show hydrophilic character. ${ }^{45}$ As for NS, due to its high hydrophilic properties and low surface activity, its adsorption at the oil/water interface is minimal and so does its ability to reduce the interfacial tension. ${ }^{44,46}$ As for ANS, ANS could transfer a large amount of polymer chains at the interface due to its strong interaction with polymer molecules. As a result, PM/ANS hybrids can further reduce the interfacial tension.

\subsection{Oil displacement test}

The main purpose of polymer flooding is to increase the viscosity of displacing fluid and reduce the water relative permeability in tertiary oil recovery. ${ }^{46}$ Because of the fact that PM/ANS-2 has the much greater viscosity than other ANS-based systems in simulated brine, PM/ANS-2 was chosen for the flooding experiment. PM flooding, PM/NS flooding and PM/ ANS-2 flooding were carried out to analyze the effect of nanoparticle type on the oil recovery factor, and the results are shown in Fig. 10 and Table 2. It can be concluded that PM/ANS-2 solution has the best injection performance among the tested samples. As post water flooding, the injection pressure is maintained at a relative high level, which means PM/ANS-2 solution can address excessive water production problems by changing the direction of flow, reducing viscous figuring, reducing the relative permeability of water $\left(k_{\mathrm{rw}}\right)$ more than the relative permeability of oil $\left(k_{\text {ow }}\right)$ through disproportionate permeability reduction and displacing fluids to unswept layers where additional oil exists. ${ }^{41}$ It is found that only $6.00 \%$ oil recovery ratio by PM flooding is obtained, whereas the oil recovery factor of PM/NS solution reaches $10.84 \%$ and PM/ANS2 solution has the best performance on enhance oil recovery with a recovery factor up to 16.30 owing to the enhanced swept volume and high viscosity under high temperature and high salinity.

\section{Conclusions}

A series of amino-functionalized nanosilica particles with different ratios between NS and APTES were prepared. The effect of nanoparticle type on the rheological property of hybrid system was studied. The results indicated all ANS-based systems exhibit better properties of salt-tolerance, heat-resistance and viscoelasticity. Among ANS-based samples, ANS-2 (NS/APTES, 6/ $0.4, \mathrm{w} / \mathrm{w}$ ) performed bestin NaCl solution whereas ANS-4 (NS/ APTES, 6/1.2, w/w) was best for the hybrid system under high $\mathrm{CaCl}_{2}$ concentrations. Furthermore, the introduction of nanoparticles also reduced the interfacial tension between crude oil and PM aqueous solution, and this reduction increased as the increase of ANS'S amine group density. The core flooding showed that the oil recovery factor of PM and PM/NS were only $6.00 \%$ and $10.84 \%$, whereas it reached $16.30 \%$ for PM/ANS-2. The obtained results indicate that the hybrid of ANS- 2 and acrylamide-based polymer has a promising prospect in polymer flooding especially for high temperature and high salinity reservoirs.

\section{Conflicts of interest}

There are no conflicts to declare.

\section{Acknowledgements}

The authors would like to appreciate the financial support from the National Natural Science Foundation of China (51874347, 21607174 and U1762212), the Fundamental Research Funds for the Central Universities (17CX02053), and the Program for Changjiang Scholars and Innovative Research Team in University (IRT_14R58). 


\section{References}

1 Z. Hu, S. Azmi, G. Raza, P. Glover and D. Wen, Energy Fuels, 2016, 30, 2791-2804.

2 M. Ann, C. Andrew, W. Kevin, F. Harry, C. Ian, M. Tim and S. Peter, Proc. R. Soc. A, 2014, 372, 20120320.

3 W. Wang, Y. Liu and Y. Gu, Colloid Polym. Sci., 2003, 281, 1046-1054.

4 D. Wever, F. Picchioni and A. Broekhuis, Prog. Polym. Sci., 2011, 36, 1558-1628.

5 F. Li, Y. Luo, P. Hu and X. Yan, J. Appl. Polym. Sci., 2016, 134, 44672.

6 C. Omurlu, H. Pham and Q. Nguyen, Appl. Nanosci., 2016, 6, 1-7.

7 T. Zhao, J. Xing, Z. Dong, Y. Tang and W. Pu, Ind. Eng. Chem. Res., 2015, 54, 10568-10574.

8 C. Niemeyer, Angew. Chem., Int. Ed., 2001, 40, 4128-4158.

9 M. Pileni, Stud. Surf. Sci. Catal., 2001, 132, 237-242.

10 A. Rogach, D. Talapin, E. Shevchenko, A. Kornowski, M. Haase and H. Weller, Adv. Funct. Mater., 2002, 12, 653664.

11 B. Ju and T. Fan, Powder Technol., 2009, 192, 195-202.

12 A. Bera and H. Belhaj, J. Nat. Gas Sci. Eng., 2016, 34, 12841309.

13 D. Arab and P. Pourafshary, Colloids Surf., A, 2013, 436, 803814.

14 E. Joonaki and S. Ghanaatian, Pet. Sci. Technol., 2014, 32, 2599-2607.

15 C. Metin and Q. Nguyen, J. Nanopart. Res., 2012, 14, 1246.

16 D. Wasan, A. Nikolov and K. Kondiparty, Curr. Opin. Colloid Interface Sci., 2011, 16, 344-349.

17 D. Wasan and A. Nikolov, Nature, 2003, 423, 156-159.

18 Z. Hu, E. Nourafkan, H. Gao and D. Wen, Fuel, 2017, 210, 272-281.

19 M. Wiśniewska, K. Terpiłowski and S. Chibowski, Powder Technol., 2013, 233, 190-200.

20 T. Narkkun, W. Jenwiriyakul and S. Amnuaypanich, J. Membr. Sci., 2017, 528, 284-295.

21 A. Munshi, V. Singh, M. Kumar and J. Singh, J. Appl. Phys., 2008, 103, 084315.

22 Z. Hu, M. Haruna, H. Gao, E. Nourafkan and D. Wen, Ind. Eng. Chem. Res., 2017, 56, 3456-3463.
23 D. Zhu, L. Wei, B. Wang and Y. Feng, Energies, 2014, 7, 38583871.

24 A. Maghzi, R. Kharrat, A. Mohebbi and M. Ghazanfari, Fuel, 2014, 123, 123-132.

25 A. Worthen, V. Tran, K. Cornell and T. Truskett, Soft Matter, 2016, 12, 2025-2039.

26 S. Sofla, L. James and Y. Zhang, Fuel, 2018, 216, 559-571.

27 M. Wiśniewska, J. Therm. Anal. Calorim., 2010, 101, 753-760.

28 J. Oberdisse, Soft Matter, 2006, 2, 29-36.

29 W. Boo, L. Sun, J. Liu and E. Moghbelli, J. Polym. Sci., Part B: Polym. Phys., 2010, 45, 1459-1469.

30 K. Terpiłowski, M. Wiśniewska and V. Zarko, J. Ind. Eng. Chem., 2015, 30, 71-76.

31 D. Zhu, Y. Han, J. Zhang, X. Li and Y. Feng, J. Appl. Polym. Sci., 2014, 131, 5829-5836.

32 J. Cao, T. Song, Y. Zhu, S. Wang and X. Wang, Energy Fuels, 2018, 32, 246-254.

33 P. Valle-Vigón, M. Sevilla and A. Fuertes, Appl. Surf. Sci., 2012, 261, 574-583.

34 C. Patel, M. Chakraborty and Z. Murthy, Part. Sci. Technol., 2015, 33, 240-245.

35 Y. Deng, J. Dixon, G. White and R. Loeppert, Colloids Surf., A, 2006, 281, 82-91.

36 C. Zheng, Y. Cheng, Q. Wei and X. Li, Colloids Surf., A, 2017, 524, 169-177.

37 B. Bradna, Q. Quadrat, L. Titkova and D. Dupuis, Acta Polym. Sin., 1997, 48, 446-449.

38 Y. Ikushima and M. Arai, Chem. Phys., 1998, 238, 455-464.

39 M. Ahmed, V. Namboodiri, A. Singh, J. Mondal and S. Sarkar, J. Phys. Chem. B, 2013, 117, 16479-16485.

40 S. Tahoun and M. Mortland, Soil Sci., 1966, 102, 314-321.

41 J. Sheng, B. Leonhardt and N. Azri, J. Can. Pet. Technol., 2015, 54, 116-126.

42 H. Xia, D. Wang, G. Wang and J. Liu, SPE Symposium on Improved Oil Recovery, Tulsa, Oklahoma, USA, 2008.

43 H. Fan, D. Resasco and A. Striolo, Langmuir, 2011, 27, 52645274.

44 T. Okubo, J. Colloid Interface Sci., 1995, 171, 55-62.

45 E. Vignati and R. Piazza, Langmuir, 2003, 19, 6650-6656.

46 J. Jung, K. Khang, H. Bo and H. Choi, J. Appl. Polym. Sci., 2013, 127, 4833-4839. 